\title{
Design of Electronic Information Board Communication System Wired and Wireless Based
}

\author{
Kevin Dwiki Novaldi Sunarsa ${ }^{1}$, Robby Saleh ${ }^{2}$ \\ ${ }^{1}$ Computer Engineering Department, Faculty of Engineering, Bina Nusantara University, Jakarta, Indonesia \\ 11480 \\ ${ }^{2}$ Computer Engineering Department, Faculty of Engineering, Bina Nusantara University, Jakarta, Indonesia \\ 11480, robby@binus.ac.id
}

\begin{abstract}
The utilization of technology as delivery of information media is widely used today and electronic information board is one of it. The purpose of this project is to make use of a wired and wireless network to make a communication system for an electronic information board. RaspberryPi module is used for storing and displaying the data which connected to monitor using HDMI connector. The device that used to send data (laptop) connected to RaspberryPi by UTP Cable (Wired) and/or Wi-Fi (Wireless). Wired network communication has an error presentation $0 \%$ while in wireless network is $0,083 \%$. Data transfer in wired and wireless communication generate an exponential curve where the value will increase bigger in a certain size.
\end{abstract}

Key words :Electronic Information Board, RaspberryPi, Wired Communication, Wireless Communication.

\section{INTRODUCTION}

As a means of delivering information, the media is divided into various types. Social media and mass media for example. Both have been widely used by the wider community, both to disseminate news in the surrounding environment and to share knowledge. Therefore, the development of a media is usually in harmony with the development of existing technology so that the wider community can get accurate information and in accordance with its portion. In addition, the use of technology is also useful to reduce the amount of excessive use of natural resources, such as the use of paper in print media.

Information board is one of the media applications that can be found in a campus, office, or the like environment. The use of this information board can help the environment so that announcements can be delivered more effectively. And now, there are many information boards that have been integrated with technology into digital or electronic information boards.

RaspberryPi is a small, inexpensive, powerful, and education-oriented computer board that was introduced in 2012. This device can be programmed according to the needs of the user. Compared to several other devices - such as
Arduino, Beaglebone Black, Phidgets, and Udoo RaspberryPi is a cheap and useful computer board with a number of input and output peripherals, and has a perfect platform for network communication interactions with different devices using space applications broad scope. By connecting Wi-Fi and connecting internet networks, this device can be used for remote communication, which makes RaspberryPi very suitable for Internet-of-Things applications [1]. Wi-Fi communication on RaspberryPi has also been widely used, and when compared with Intel Edison devices, this device can be said to have stable data so that it is used as a reference in several studies (Aliaa Essameldin, Khaled Harras).

The design of this information board will use a client/server model where RaspberryPi as a module will function to receive and display content sent by the user using a laptop with wired and wireless communication, then the content will be displayed via an HDMI connection to the display screen. Wired or wired communication in this design uses UTP cable and wireless or wireless communication in this design uses Wi-Fi that is already available on raspberry devices.

"Samba" is open-source software that provides seamless files and print services on SMB / CIFS clients. This software is considered user-friendly because it can run on Linux / UNIX servers and Window-based clients. The Samba server consists of two main programs, including smbd and nmdb. The four main features found in Samba include File and Print Service, Authentication and Authorization, Name Resolution and Service Announcement. [2]. In this design, Samba is used as remote file access and connects directory servers with clients.

\subsection{Purpose}

The purpose of this Electronic Information Board Communication System Design is to implement the infrastructure network as a communication system between client (laptop) and server (RaspberryPi) either by using UTP cable or wired wirelessly using Wi-Fi.

\section{RESEARCH METHODOLOGY}

The system used in this design is a wired or wired and wireless based network communication system. The RaspberryPi module, which acts as an electronic information board, is connected to a LAN network through an access 
point and/or an Ethernet cable where the module functions as a server to store data and the user functions as a client. Following is a description of the network communication system used in the design.

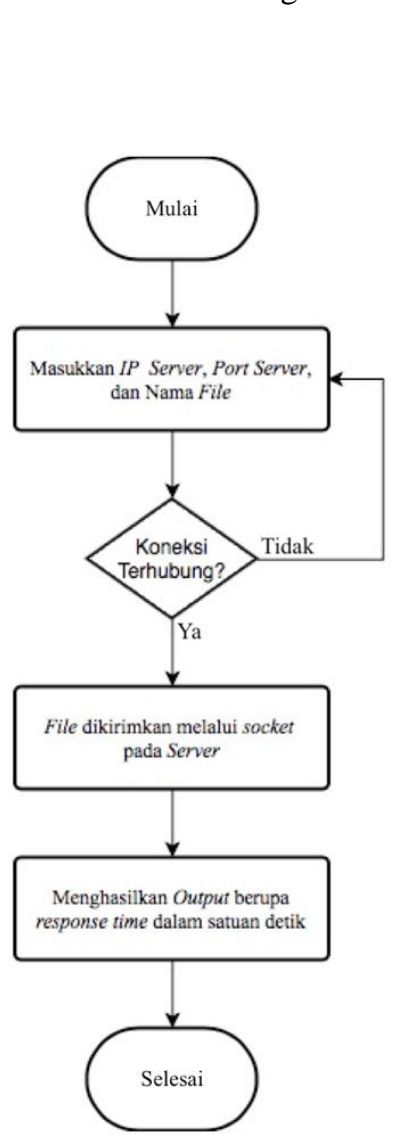

(a)

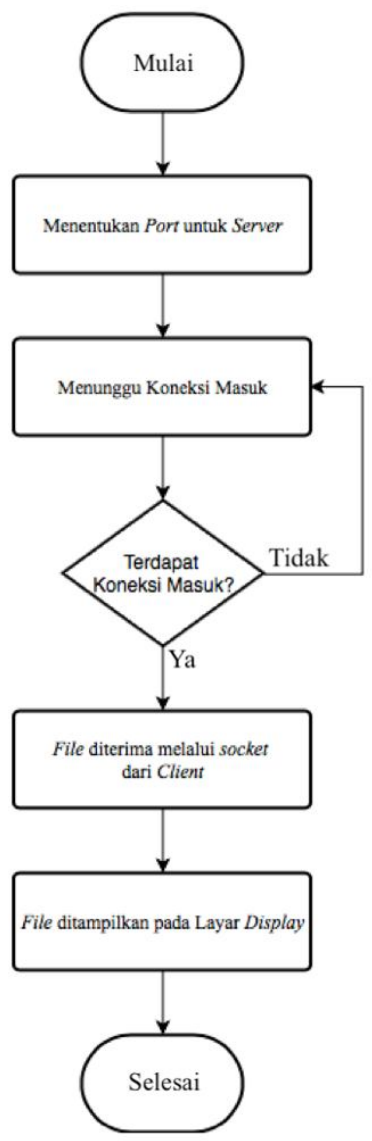

(b)
Figure 1: (a) Client System Flowchart, (b) Server System Flowchart

The client here functions to send data or content on an electronic information board, or in this case the RaspberryPi module, via a socket using IP and Port. This flowchart describes the work system of the client or device.

The server functions to receive and hold data sent by the client through the socket using IP and Port. Data stored on the server will be displayed on a monitor connected to the RaspberryPi module using an HDMI connection. Here is a flowchart that describes the working system of the server.
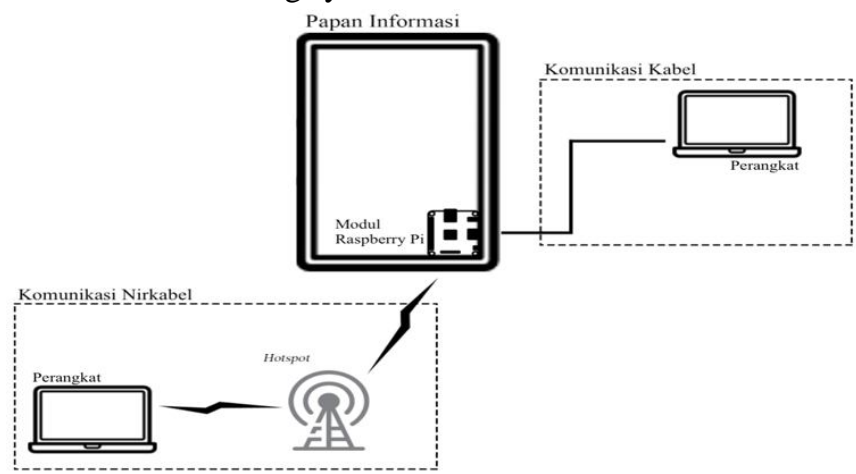

Figure 2: Design Network Diagram
The network diagram above explains the overall picture of the communication system used in the design of devices and modules. Device or user can be connected in two ways, wired communication and wireless communication. In wired communication, the device is connected directly to the RaspberryPi module by using an Ethernet or UTP cable. While in wireless communication, the device is connected to the module through an intermediary hotspot or access point so that between the device and the module will be connected to one network.

The server equipment used is the RaspberryPi Model B module which functions as a data storage and displays content via an HDMI connection. The device used as a display is a 5inch HDMI Display. Apart from this device, other displays can also be used as long as they have an HDMI connection such as an LCD TV. Here are the specifications of the 5inch HDMI Display device.

Table 1: Display Device Specifications

\begin{tabular}{|l|l|}
\hline Size & $5.0($ inch $)$ \\
\hline SKU & 6320629805 \\
\hline Resolution & $800 \times 480($ dots $)$ \\
\hline Dimensions & $121.11 * 77.93(\mathrm{~mm})$ \\
\hline Weight & $175(\mathrm{~g})$ \\
\hline
\end{tabular}

(3)

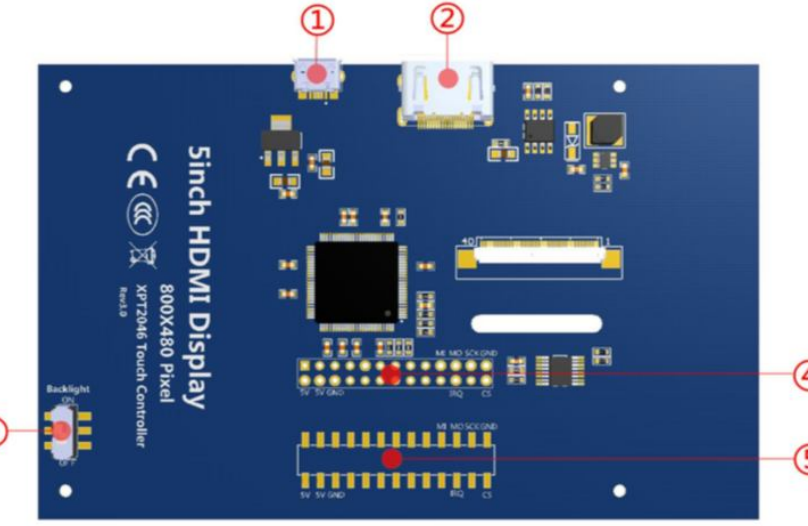

Figure 3: Pin-out Display Device "5inch HDMI Display" (5inch HDMI Display Datasheet)

1. USB interface: Power 5V from USB.

2. HDMI interface: for HDMI transmission.

3. Backlight Power Switch: set the backlight display to be turned on and off to save power.

4. $13 * 2$ Pin Socket: 5V Power from RaspberryPi on the LCD, simultaneously sending touch signals to raspberry.

5. Extended interface: expanding Pin-to-Pin signal $13 * 2$ pin socket.

Following are the server device specifications, or in this case the RaspberryPi module.

Table 2: Server Device Specifications[3]

\begin{tabular}{|l|l|}
\hline CPU & Quad Cortex A53 @ 1.2 GHz \\
\hline GPU & $400 \mathrm{MHz}$ Video Core IV \\
\hline RAM & $512 \mathrm{MB}$ SDRAM \\
\hline Ethernet & $10 / 100$ \\
\hline Wireless & $802.11 \mathrm{n} /$ Bluetooth 4.0 \\
\hline Video Output & HDMI / Composite \\
\hline
\end{tabular}




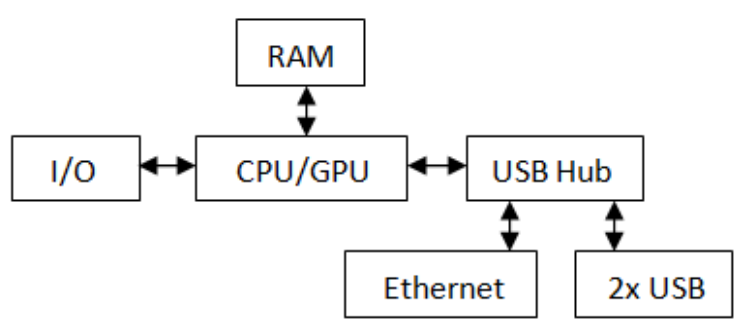

Figure 4: Internal Hardware from RaspberryPi

In the block diagram above for models $\mathrm{A}, \mathrm{B}, \mathrm{A}+, \mathrm{B}+$; the bottom two blocks and the rightmost block are not available on models $\mathrm{A}$ and $\mathrm{A}+$ (these three blocks are on a chip that usually has three USB hub ports, with a USB Ethernet adapter connected to one of the ports). In models $\mathrm{A}$ and $\mathrm{A}+$ the USB port is directly connected to the SoC. On the B + model, the chip has five hub points, with four USB ports available compared to the two ports on model B. [4].

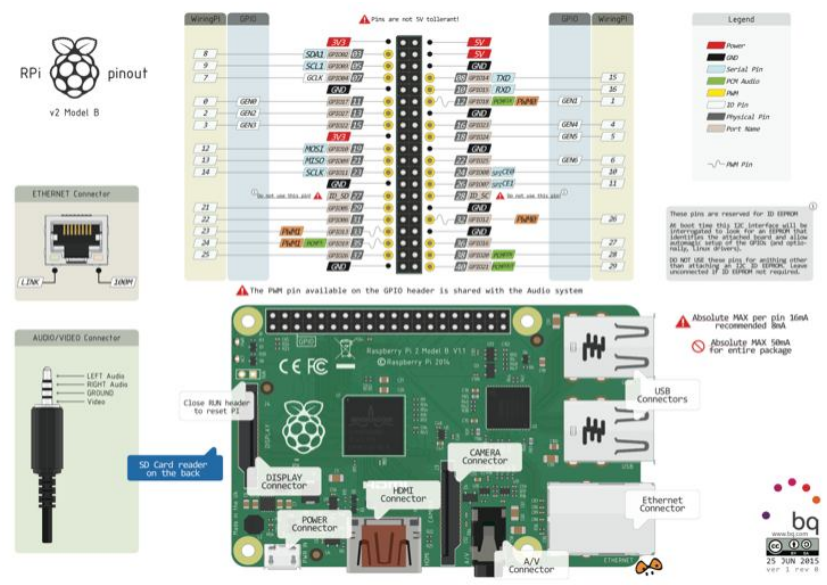

Figure 5:RaspberryPi 3 Server Device Pin-out Model B (http://www.pighixxx.net/wpcontent/uploads/2015/06/raspberry.pdf)

The parameters or data measured in this design include the speed of data transmission or response time and the size or size of the data sent and received. Measurements were made using socket programs found on server and client devices.

Reliable system presentations are taken from a combination of average data transmission speed or response time which is measured based on different data sizes. The results of a reliable presentation of the system will produce a data sending reliability curve.

\section{RESULT AND DISCUSSION}

In this design, there are several files of different sizes that are used as sample data. Then the data is sent from the client or user to the server using a socket. The output displayed is in the form of data transmission speed and size of the data sent. The file used as a sample consists of several data sizes or sizes, including $10 \mathrm{~KB}, 90 \mathrm{~KB}, 200 \mathrm{~KB}, 400 \mathrm{~KB}, 600 \mathrm{~KB}$, $800 \mathrm{~KB}, 1 \mathrm{MB}, 2 \mathrm{MB}, 5 \mathrm{MB}, 10 \mathrm{MB}, 30 \mathrm{MB}, 50 \mathrm{MB}, 85 \mathrm{MB}$, $85 \mathrm{MB}, 100 \mathrm{MB}, 450 \mathrm{MB}, 700 \mathrm{MB}, 700 \mathrm{MB}$ and $1 \mathrm{~GB}$.

From sending 18 sample data with different data sizes or sizes, 20 trials were conducted for each data size or in total

of 360 data. The data is then entered into a table and illustrated through a line graph.

The data displayed on the information board in the form of image files (.jpg, .jpeg) can be said to be $100 \%$ successful. The following is an example of the display image on the display using VNC Viewer.

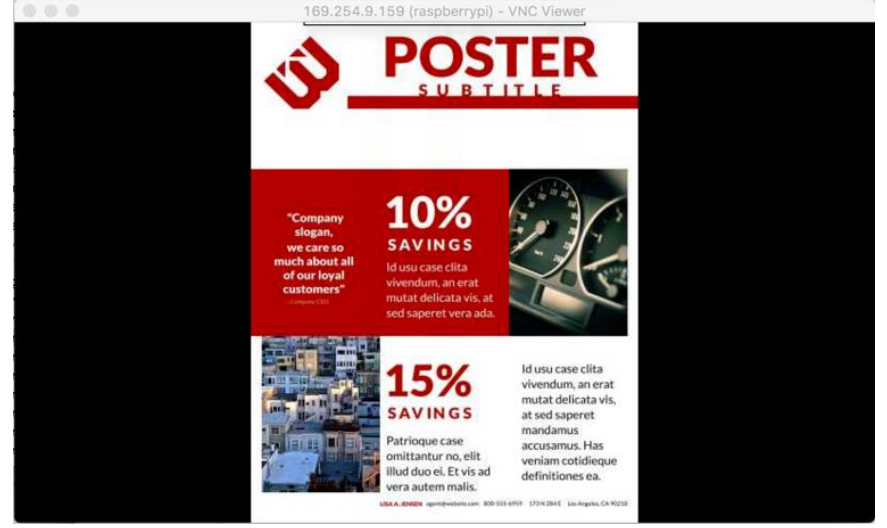

Figure 6: Example of Display Content on Display

From 360 experiments, there was a failure in sending data of 3 data or in percentage of $0.083 \%$ on wireless networks. As for wired networks, data transmission does not fail or in the percentage of $0 \%$. If concluded from the two percentage values, the communication system on wired and wireless networks can be said to be reliable. In addition, we also get the average value of sending data from each data size that can also be illustrated on a graph. Here are the average values from the data transmission trial.

Table 3: Average Data of Experiment Results

\begin{tabular}{|l|r|l|l|}
\hline \multicolumn{1}{|c|}{ Data Samples } & \multicolumn{1}{|c|}{$\begin{array}{c}\text { Data Size } \\
\text { (bytes) }\end{array}$} & $\begin{array}{c}\text { Wired } \\
\text { Network } \\
\text { Average (s) }\end{array}$ & $\begin{array}{c}\text { Wireless } \\
\text { Network } \\
\text { Average (s) }\end{array}$ \\
\hline Sample10kb.jpg & 9.591 & 0,2865 & 0,33775 \\
\hline Sample90kb.jpg & 92.841 & 0,464745 & 0,1689 \\
\hline 200kbSample.jpeg & 203.395 & 0,551871 & 0,347307 \\
\hline Sample400kb.jpg & 430.355 & 0,20011155 & 0,6190145 \\
\hline Sample600kb.pptx & 625.661 & 0,300789 & 0,890571 \\
\hline Sample800kb.jpg & 830.335 & 0,458611 & 1,142231 \\
\hline Sample1mb.jpg & 1.065 .560 & 0,618313 & 1,404879 \\
\hline Sample2mb.jpg & 2.419 .685 & 1,300598 & 3,3088355 \\
\hline Sample5mb.jpg & 5.322 .618 & 4,42609 & 1,8358935 \\
\hline Sample10mb.mp3 & 10.329 .339 & 5,9935555 & 4,638427 \\
\hline Sample30mb.pptx & 29.727 .999 & 7,0049815 & 6,3716605 \\
\hline Sample50mb.MOV & 55.397 .840 & 6,429658 & 11,9959955 \\
\hline Sample85mb.MOV & 87.813 .312 & 9,409334 & 16,498815 \\
\hline Sample100mb.mp4 & 112.084 .388 & 13,290221 & 22,69587632 \\
\hline Sample250mb.psd & 276.297 .232 & 40,831469 & 65,0459485 \\
\hline Sample450mb.m4v & 465.752 .331 & 75,6072005 & 109,374938 \\
\hline Sample700mb.psd & 705.775 .234 & 114,6998035 & 176,409979 \\
\hline Sample1gb.pkg & 1.378 .378 .228 & 208,1064275 & 317,6429005 \\
\hline
\end{tabular}




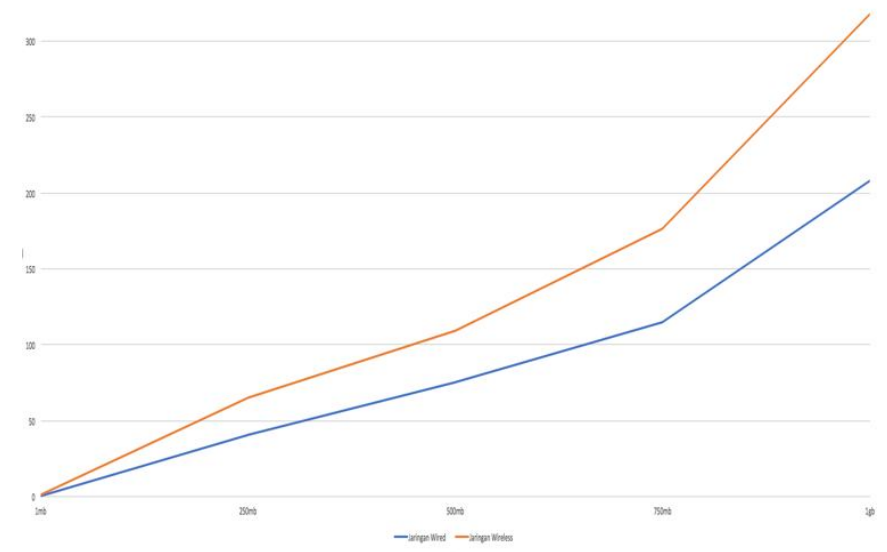

Figure 7: Average Graph of Experimental Results

Based on the picture above, it can be concluded that sending data in this design results in an exponential curve, where the value will increase in size at a certain size, in contrast to a linear curve that has a value that is perpendicular to its size.

\section{CONCLUSION}

Based on the data generated, the conclusions of the Wired and Wireless-based Electronic Information Board Communication System Design are as follows.

1. Image data sent on the information board in the form of file .jpg 'and'.jpeg 'files $100 \%$ successfully displayed.

2. Based on data obtained from 360 attempts, communication networks using cable or (wired) have a percentage of data transmission failures of $0 \%$, while on wireless or wireless communication networks of $0.083 \%$.

3. The communication system in this design can already be said to be reliable when viewed from the percentage of data transmission failures.

\section{REFERENCES}

[1] P. B. M. Mirjana, V. Vladimir, D. Nikola, M. Vladimir, Raspberry $P i$ as Internet of Things hardware: Performances and Constrains. Bosnia and Herzegovina: University of East Sarajevo, 2015.

[2] C. S. W. Cheah, J. Jayanand, "Exploring IOT Application Using Raspberry Pi," Int. J. Comput. Networks Appl., vol. 2, no. 1, pp. 27-34, 2015.

[3] Raspberrypi.org, "Raspberry Pi Model B: Specification," Raspberrypi.org, 2016. [Online]. Available:

https://www.raspberrypi.org/products/raspberry-pi-3model-b/. [Accessed: 18-Aug-2017].

[4] R. P. V. Sejal, "Raspberry Pi Technology," Int. J. Adv. Res. Comput. Sci. Softw. Eng., vol. 5, no. 4, pp. 37-40, 2015. 